\title{
Associação do loco BoLA-DRB3.2 com produção de leite em bovinos da raça Gir
}

[Association of BoLA-DRB3.2 locus with bovine milk production in Gir breed]

\author{
M.A. Machado ${ }^{1}$, C.S. Nascimento ${ }^{2}$, M.L. Martinez ${ }^{1}$, M.V.G.B. Silva ${ }^{1}$, A.L. Campos $^{1}$, \\ R.L. Teodoro ${ }^{1}$, R.S. Verneque ${ }^{1}$, S.E.F. Guimarães ${ }^{3}$ \\ ${ }^{1}$ Embrapa Gado de Leite \\ Rua Eugênio do Nascimento, 610 - Dom Bosco \\ 36038-330 - Juiz de Fora, MG \\ ${ }^{2}$ Bolsista de Apoio Técnico da Fapemig \\ ${ }^{3}$ Departamento de Zootecnia - Universidade Federal de Viçosa
}

\begin{abstract}
RESUMO
A associação entre os alelos do loco BoLA-DRB3.2, identificados pela técnica de PCR-RFLP, e a produção de leite na raça Gir foi estudada por meio da análise de dados moleculares e fenotípicos de 424 vacas Gir, utilizando um modelo misto, sob modelo animal. Os dados moleculares consistiam dos genótipos dos animais para os alelos do loco BoLA-DRB3.2 e os dados fenotípicos eram referentes à produção de leite em até 305 dias de lactação. O loco é altamente polimórfico nesta raça, sendo identificados sete alelos (BoLA-DRB3.2*4, *8, *11, *19, *28, *41 e *48) que não haviam sido encontrados em animais zebuínos. Dois alelos $(* 16$ e *29) estavam significativamente associados com maiores produções de leite, sugerindo que o próprio loco BoLA-DRB3.2 ou um QTL a ele ligado influencia a produção de leite de vacas Gir.
\end{abstract}

Palavras-chave: BoLA-DRB3, PCR-RFLP, gene candidato, bovinos, Gir

\begin{abstract}
The association between BoLA-DRB3.2 alleles identified by PCR-RFLP and milk production in Gir breed was studied using molecular and phenotypic data of 424 Gir cows. Genetic data consisted of animal genotypes for BoLA-DRB3.2 alleles and 305-day-milk-yield. The association between BoLA-DRB3.2 alleles and a putative QTL affecting the trait was investigated by mixed model with an animal model. BoLA-DRB3.2 locus was found to be highly polymorphic in Gir breed, showing seven alleles (BoLADRB3.2*4, *8, *11,*19, *28, *41 $e^{* 48)}$ that have not been yet described in Zebu animals. Two BoLADRB3 alleles $\left(* 16 e^{* 29)}\right.$ were significantly associated with milk production, suggesting that BoLADRB3.2 locus itself or a linked QTL influences 305-day-milk yield of Gir cows.
\end{abstract}

Keywords: BoLA-DRB3, PCR-RFLP, candidate gene, bovine, Gir

Trabalho financiado parcialmente pelo CNPq.

Recebido para publicação em 17 de dezembro de 2003

Recebido para publicação, após modificações, em 29 de setembro de 2004

* Autor para correspondência (corresponding author)

E-mail: martinez@cnpgl.embrapa.br 


\section{INTRODUÇÃO}

O complexo maior de histocompatibilidade bovina (BoLA), mapeado no braço curto do cromossomo 23 dessa espécie (Fries et al., 1988), consiste de vários locos fortemente ligados entre si, cujos genes codificam moléculas da superfície celular relacionadas à resposta imunológica (Alizadeh et al., 2003). Esses genes formam um sistema genético polimórfico, encontrado em vertebrados superiores e que codificam duas classes de proteínas (I e II) da superfície das células do sistema imunológico. Os produtos dos genes das classes I e II podem ser distinguidos por meio de suas características estruturais e funcionais.

Na classe II, em bovinos, há predominância do loco DR, formado por duas cadeias: uma monomórfica (DRA) e outra altamente polimórfica, denominada DRB3 (Sharif et al., 2003). Segundo Sena et al. (2003), mais de 80 alelos foram identificados neste loco (http://www.ri.bbsrc.ac.uk/bola/drtab.htm), e a maior parte do polimorfismo está concentrada no exon 2 do gene BoLA-DRB3 (BoLA-DRB3.2).

O loco BoLA tem sido amplamente estudado nos últimos 20 anos em razão de sua influência sobre as características produtivas e às relacionadas à saúde animal. $\mathrm{O}$ efeito sobre a saúde animal pode ser resultante da ação direta dos alelos BoLA sobre as funções imunológicas, enquanto o efeito indireto sobre as características de produção pode ser explicado de duas maneiras: a primeira é que indivíduos que apresentem melhores condições gerais de saúde podem ser mais produtivos; a segunda é a possível existência de ligação do loco BoLA com locos de características quantitativas.

Em ruminantes, os locos BoLA são extremamente polimórficos e vários estudos têm confirmado a influência direta e significativa dos alelos das classes I e II do BoLA sobre as características de saúde em bovinos de leite. Weigel et al. (1990) verificaram associação entre alguns alelos da classe I do BoLA com o aumento da resistência à mastite clínica e a redução do custo com a saúde em vacas da raça Holandesa, nos Estados Unidos. Associações significativas entre os alelos da classe I e a resistência à mastite e à cetose foram encontradas em bovinos, na Noruega, por
Mejdell et al. (1994). Possíveis associações dos alelos da classe I do BoLA com a incidência de leucose bovina e dos alelos da classe II do BoLA e com resistência à mastite foram relatadas por Lewin et al. (1988) e Detilleux (1993), respectivamente.

Em relação às características de desempenho, Weigel et al. (1990) relataram associação do alelo A11 da classe I do BoLA com a diminuição da quantidade e do teor de gordura, e citaram a influência do alelo A14 sobre o aumento da produção de leite e de gordura, da porcentagem de gordura e da receita sobre o custo da alimentação. Batra et al. (1996) encontraram associação significativa entre o alelo A14 e o aumento da vida produtiva, quantidade de leite, proteína e lactose na raça Holandesa, no Canadá.

Na raça Suíça Braunvieh, Arriens et al. (1996) verificaram associação significativa entre o alelo A22 e aumento na produção de gordura. Segundo Batra et al. (1989), a substituição do alelo W10 pelo alelo W6.1 estava associada ao aumento na quantidade de proteína, enquanto o alelo W10 estava relacionado a maiores teores de gordura. Os resultados obtidos por Hines et al. (1986) demonstraram que a média da porcentagem de gordura associada ao alelo W10 era de $0,15 \%$ maior que a média para outros quatro alelos.

Segundo Rothschild e Soller (1997), uma das vantagens da utilização de genes candidatos, se o próprio gene for o responsável direto pelo fenótipo, reside no fato de a associação não ser influenciada por recombinação, esperando-se que o efeito do gene seja estável através das gerações e, conseqüentemente, não necessite ser restabelecido em cada geração. Quando identificado e verificado o efeito de um gene candidato, ele pode ser, imediatamente, utilizado na seleção assistida por marcadores, com resultados satisfatórios, como os encontrados por Maillard et al. (2003), que observaram redução acentuada na prevalência de dermatofilose (Dermatophilus congolensis), ao selecionarem animais contra os alelos 9 e 45 do BoLADRB3.2, em um rebanho Brahman, na Martinica.

Apesar da importância do complexo BoLA no desempenho de características produtivas e de saúde, não foram encontrados estudos relatando a associação dos alelos desse complexo em animais zebuínos selecionados para leite no 
Brasil. Este trabalho teve o objetivo de estudar a associação entre os alelos do loco DRB3.2 do sistema imunológico bovino (BoLA) com a produção de leite em até 305 dias de lactação em vacas da raça Gir.

\section{MATERIAL E MÉTODOS}

Amostras de sangue de 470 vacas da raça Gir, filhas de 99 touros e criadas em dois rebanhos do Estado de Minas Gerais, foram coletadas e enviadas para o Laboratório de Genética Molecular da Embrapa Gado de Leite para extração de DNA e genotipagem para o loco BoLA-DRB3.2.

O DNA foi extraído a partir das células brancas das amostras de sangue, utilizando protocolo contendo tampão salino e proteinase $\mathrm{K}$, sendo as proteínas removidas com fenol/clorofórmio. As amostras de DNA foram analisadas em espectrofotômetro visando determinar a quantidade e qualidade.

A amplificação do loco BoLA-DRB3.2 foi realizada utilizando a técnica de Nested PCR, conforme descrito por van Eijk et al. (1992). Para a primeira amplificação, foram utilizados os primers HLO30 (5-ATCCTCTCTCTGCAGCACATTTCC-3') e HLO31 (5'-TTAAATTCGCGCTCACCTCGCCGC T-3'). Para a segunda amplificação, foram utilizados os primers HLO30 e HLO32 (5'TCGCCGCTGCCACAGT-3'), visando aumentar a especificidade da reação de PCR e diminuir a presença de heteroduplexes. O primer HLO32 consiste inteiramente de nucleotídeos da extremidade 3' do exon 2 e tem oito nucleotídeos sobrepostos com a extremidade 3' do primer HLO31.

A primeira reação de $\mathrm{PCR}$ consistia de 10 ciclos de $94^{\circ} \mathrm{C}$ por $60 \mathrm{seg}, 60^{\circ} \mathrm{C}$ por 120 seg e $72^{\circ} \mathrm{C}$ por 60 seg. Foram utilizados $12,5 \mathrm{ng}$ de DNA para a reação de PCR contendo uma unidade de Taq polimerase; $100 \mu \mathrm{M}$ de dNTPs; $0,2 \mu \mathrm{M}$ de cada primer; $10 \mathrm{mM}$ de Tris- $\mathrm{HCl}(\mathrm{pH} 8,0) ; 2,5 \mathrm{mM}$ de $\mathrm{MgCl}_{2}$ e $50 \mathrm{mM}$ de $\mathrm{KCl}$. A segunda reação consistia de 30 ciclos de $94^{\circ} \mathrm{C}$ por 60 seg, $65^{\circ} \mathrm{C}$ por 30 seg, utilizando-se $1,4 \mu \mathrm{l}$ da primeira reação de PCR, num volume final de $35 \mu$, contendo uma unidade de Taq polimerase; $100 \mu \mathrm{M}$ de dNTPs; $0,2 \mu \mathrm{M}$ de cada primer; $10 \mathrm{mM}$ de Tris$\mathrm{HCl}(\mathrm{pH} 8,0) ; 2,5 \mathrm{mM}$ de $\mathrm{MgCl}_{2}$ e $50 \mathrm{mM}$ de $\mathrm{KCl}$.
As reações foram realizadas no termociclador GeneAmp PCR System 9600 da Applied Biosystems.

Os produtos gerados na segunda reação de PCR foram visualizados em géis de poliacrilamida nativo a $5 \%$ (500 volts por $1 \mathrm{~h})$, para padronizar a quantidade de material amplificado e detectar possíveis falhas de amplificação. Para isso, foram utilizados $5 \mu \mathrm{l}$ do volume final da reação. Após essa etapa, $10 \mu \mathrm{l}$ da segunda reação de PCR foram digeridos por duas horas a $37^{\circ} \mathrm{C}$, separadamente, com cinco unidades das enzimas $R s a$ I e Hae III, e por $2 \mathrm{~h}$ a $60^{\circ} \mathrm{C}$ para a enzima Bsty I, num volume final de $15 \mu$ l. Após digestão, as enzimas foram inativadas por $15 \mathrm{~min}$ a $80^{\circ} \mathrm{C}$. Em seguida, os fragmentos foram submetidos a eletroforese vertical em géis de poliacrilamida nativo a $12 \%$ ( 800 volts por $3 \mathrm{~h})$, utilizando placas com $35 \mathrm{~cm}$ de altura para garantir uma perfeita separação dos fragmentos. Os géis foram corados com nitrato de prata e os fragmentos foram detectados com o auxílio de padrões de 25 e 10pb. A nomenclatura dos fragmentos foi realizada conforme descrito por van Eijk et al. (1992), International... (1992) e Maillard et al. (1999).

As freqüências dos alelos do loco BoLA-DRB3.2 para as 470 vacas foram calculadas por meio de contagem direta.

Para obter maior consistência dos dados nos estudos de associação, foram eliminadas as informações das vacas cuja freqüência era inferior a $1 \%$ dentro da classe do alelo ou do genótipo BoLA, nas análises envolvendo cada um desses grupos. Satisfeitas essas restrições, restaram 1.140 registros de produção de leite, em até 305 dias, das três primeiras lactações de 424 vacas, filhas de 88 touros e com partos entre os anos de 1986 e 2003, que foram pré-ajustados para a idade adulta. Os grupos contemporâneos foram caracterizados pela combinação de ano e estação de parto, pois os registros foram analisados dentro de cada rebanho. Os rebanhos utilizados neste estudo apresentam base genética semelhante e foram selecionados para produção de leite por mais de 50 anos ( $\cong 8$ gerações); todavia, foram submetidos a diferentes intensidades de seleção. Os dados fenotípicos foram provenientes do Serviço de Controle Leiteiro da Associação Brasileira dos Criadores 
de Gir Leiteiro (ABCGIL) e compõem o Arquivo Zootécnico Nacional de Gado de Leite, gerenciado pela Embrapa Gado de Leite.

Conforme proposto por Israel e Weller (1998), o modelo [1] incluiu os efeitos de gene candidato, como a seguir:

$y=X h+Q q+Z_{1} a+Z_{2} p+\varepsilon$

em que $\mathrm{y}=$ vetor de registro de produções; $\mathrm{X}, \mathrm{Z}_{1}$ e $Z_{2}=$ matrizes incidência relativas aos efeitos fixos e aleatórios; $h, a, p$ e $\varepsilon=$ vetores de soluções para os efeitos fixos, genético aditivo, permanente de ambiente e residual, respectivamente, $\mathrm{q}=$ vetor de efeitos fixos para os genótipos do gene candidato e $\mathrm{Q}=$ matriz de incidência para esse efeito. $\mathrm{O}$ efeito de anoestação do parto foi assumido como fixo e os efeitos genético aditivo, permanente de ambiente e residual foram assumidos como aleatórios, tendo distribuição normal, médias iguais a zero e variâncias $\sigma_{\mathrm{a}}^{2}, \sigma_{\mathrm{p}}^{2}$ e $\sigma_{\mathrm{e}}^{2}$, respectivamente. As equações do modelo misto para o modelo [1] são:

$$
\left[\begin{array}{cccc}
X^{\prime} X & X^{\prime} Q & X^{\prime} Z_{1} & X^{\prime} Z_{2} \\
Q^{\prime} X & Q^{\prime} Q & Q^{\prime} Z_{1} & Q^{\prime} Z_{2} \\
Z_{1}^{\prime} X & Z_{1}^{\prime} Q & Z_{1}^{\prime} Z_{1}+\lambda A^{-1} & Z_{1}^{\prime} Z_{2} \\
Z_{2}^{\prime} X & Z_{2}^{\prime} Q & Z_{2}^{\prime} Z_{1} & Z_{2}^{\prime} Z_{2}+\gamma
\end{array}\right]\left[\begin{array}{c}
\hat{h} \\
\hat{q} \\
\hat{a} \\
\hat{p}
\end{array}\right]=\left[\begin{array}{c}
X^{\prime} y \\
Q^{\prime} y \\
Z_{1}^{\prime} y \\
Z_{2}^{\prime} y
\end{array}\right]
$$

em que $\lambda=\sigma_{\mathrm{e}}^{2} / \sigma_{\mathrm{a}}^{2}, \gamma=\sigma_{\mathrm{e}}^{2} / \sigma_{\mathrm{p}}^{2}$ e $\mathrm{A}^{-1}$ é a inversa da matriz dos numeradores dos coeficientes de parentesco de Wrigth.

No modelo [1], os números de linhas e de colunas na matriz $\mathrm{Q}$ são iguais aos números de animais e de genótipos BoLA, respectivamente. Os elementos das linhas da matriz $\mathrm{Q}$ são iguais à unidade quando o animal apresentar o genótipo correspondente à coluna e iguais a zero, para os outros elementos.

Os efeitos de um gene sobre características quantitativas podem ser confundidos com efeitos genéticos não-aleatórios em virtude do parentesco entre indivíduos compartilhando determinado alelo. Dessa forma, para estimar o efeito direto de cada alelo, os registros de produção de leite em até 305 dias também foram analisados por meio de um modelo de substituição gênica, o qual considera o efeito aditivo de um alelo no gene BoLA. Tal modelo pode ser representado matricialmente, como:

$y=X h+M m+Z_{1} a+Z_{2} p+\varepsilon$

em que $m=$ vetor incluindo os efeitos fixos de substituição gênica para diferentes alelos BoLA representados por coeficientes de regressão e $\mathrm{M}$ $=$ matriz contendo 0,1 ou 2 , representando o número de cópias de determinado alelo BoLA presente em cada indivíduo. $\mathrm{O}$ modelo de substituição gênica expressa o efeito de um alelo particular após a remoção dos efeitos aditivos de outros alelos portados por outros animais. $\mathrm{O}$ modelo [2] também foi utilizado para análise conjunta dos genótipos considerando possíveis interações epistáticas.

Todas as análises foram realizadas por meio do PROC MIXED do sistema SAS (User's..., 2000), resultando em maior flexibilidade na modelagem não somente das médias, mas também das (co)variâncias.

\section{RESULTADOS E DISCUSSÃO}

O produto de amplificação da segunda reação de PCR gerou fragmentos de $284 \mathrm{pb}$ ou $281 \mathrm{pb}$, quando o animal possuía a deleção de $3 \mathrm{pb}$, como descrito por van Eijk et al. (1992). Os produtos de amplificação apresentaram pouca quantidade de heteroduplexes, possibilitando a realização da etapa de digestão dos fragmentos, sem o comprometimento da identificação dos alelos. A utilização de placas com $35 \mathrm{~cm}$ para separação eletroforética dos fragmentos permitiu a detecção dos diversos padrões de corte gerados pelas três enzimas de restrição (Fig. 1). Para a enzima $R s a \mathrm{I}$, foram encontrados 18 padrões de corte do total de 25 descritos por van Eijk et al. (1992). Para a enzima BstYI, todos os padrões descritos foram encontrados. Para a enzima HaeIII, foram encontrados cinco padrões de corte do total de nove descritos pelo autor. 


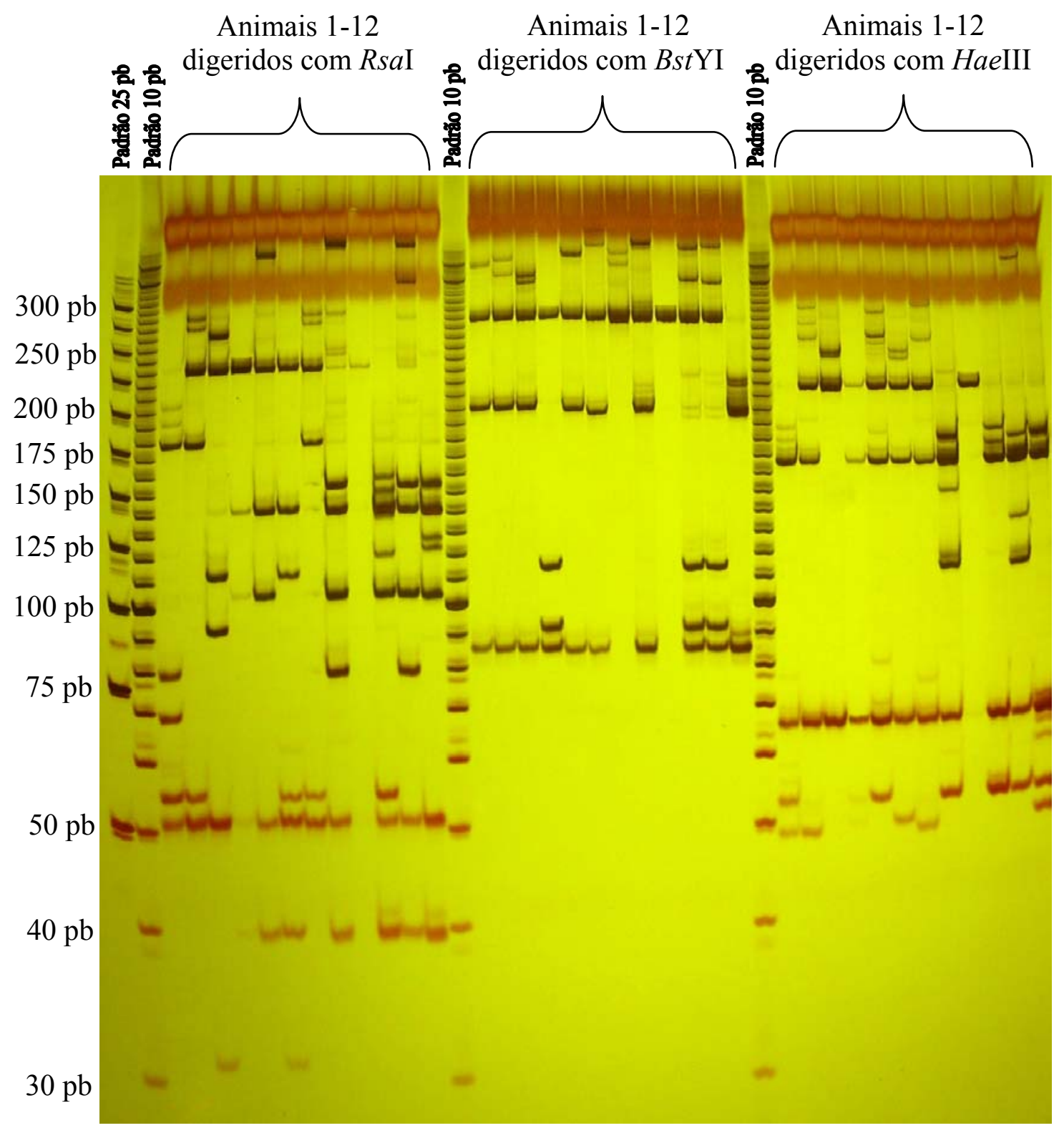

Figura 1. Gel de poliacrilamida nativo (12\%) mostrando o padrão de digestão do DNA de 12 animais para três enzimas polimórficas para o fragmento de 284pb do gene BoLA - DRB3.2. 
Com a combinação dos diferentes padrões de corte das três enzimas, 54 alelos diferentes podem ser detectados, segundo van Eijk et al. (1992). Desse total, 27 alelos foram identificados nas duas populações.

O grande número de alelos (27) identificados nos dois rebanhos demonstra que a raça Gir apresenta um alto polimorfismo para o loco BoLA-DRB3.2 (Tab. 1). No trabalho de Mota et al. (2002), o primeiro estudo a respeito do loco BoLA-DRB3.2 nessa raça, foram observados 17 alelos diferentes, sendo alguns deles já encontrados na raça Brahman por Maillard et al. (1999). Neste estudo, foram identificados sete alelos (BoLA-DRB3.2*4, *8, *11, *19, *28,*41 e*48) que não haviam sido citados em zebuínos.

Tabela 1. Frequência alélica do loco BoLADRB3.2* observada para 470 animais da raça Gir

\begin{tabular}{lccc}
\hline \multirow{2}{*}{ Alelo } & \multicolumn{3}{c}{ Freqüência por rebanho $(\%)$} \\
\cline { 2 - 4 } & $\mathrm{A}$ & $\mathrm{B}$ & Total \\
\hline 3 & 0,70 & 3,10 & 2,30 \\
4 & - & 0,30 & 0,20 \\
5 & - & 6,10 & 4,10 \\
6 & 0,30 & 6,10 & 4,30 \\
7 & 15,70 & 0,50 & 5,30 \\
8 & - & 1,10 & 0,70 \\
10 & - & 0,20 & 0,10 \\
11 & 0,70 & 5,50 & 3,90 \\
15 & - & 3,30 & 2,20 \\
16 & 12,00 & 11,40 & 11,60 \\
18 & - & 2,70 & 1,80 \\
19 & 1,00 & 0,30 & 0,50 \\
20 & 0,30 & 24,70 & 16,90 \\
23 & 0,70 & - & 0,20 \\
27 & 19,30 & 11,30 & 13,80 \\
28 & - & 0,50 & 0,30 \\
29 & 27,00 & 1,10 & 9,40 \\
31 & 0,70 & 6,40 & 4,60 \\
33 & - & 0,20 & 0,10 \\
35 & 9,30 & 6,70 & 7,60 \\
41 & - & 0,30 & 0,20 \\
42 & 10,70 & 0,90 & 4,00 \\
46 & - & 0,20 & 0,10 \\
47 & - & 0,20 & 0,10 \\
48 & 0,70 & 0,50 & 0,50 \\
51 & - & 1,10 & 0,70 \\
54 & 100,00 & 100,00 & 100,00 \\
Total & dos & alelos & está de \\
A designação & acordo com o \\
International.. 1992$).$ & & \\
& & &
\end{tabular}

$\mathrm{Na}$ Tab. 1 verifica-se que as freqüências alélicas variaram de 0,10 a 16,90 e a soma das freqüências dos seis alelos mais comuns (BoLADRB3.2*7, *16, *20,*27, *29 e *35) foi de $64,6 \%$. Altos graus de polimorfismo também foram encontrados por Sharif et al. (1998b), na raça Holandesa, e por Gilliespie et al. (1999), na raça Jersey. Dietz et al. (1997) relataram que os locos BoLA-DRB3*8, *11,*16, *22, *23 e *24 computavam $70,3 \%$ da freqüência total, em animais da raça Holandesa, entretanto, Gilliespie et al. (1999) observaram que a soma das freqüências dos locos BoLA-DRB3*8, *10,*15, $* 21$, *36 e *ibe foi de 73,9\%. Comparando-se esses resultados, pode-se inferir que à exceção do loco $* 8$, encontrado nas raças citadas, há grandes diferenças entre elas no que se refere à presença e/ou à freqüência dos alelos.

No rebanho A foram observados 15 diferentes alelos em 150 vacas, enquanto no rebanho B, cuja população avaliada era composta por 320 vacas, a diversidade foi maior, sendo observados 26 alelos, o que pode ser explicado pelo tamanho da amostra. Dos 15 alelos presentes na população A, apenas um alelo $(* 23)$ não estava presente na população $\mathrm{B}$ provavelmente atribuído à população fundadora. $\mathrm{Na}$ Tab. 1 verifica-se que 14 alelos foram comuns aos dois rebanhos e, dentre esses, destacaram-se os alelos $* 16$ e *27, encontrados em altas freqüências nos dois rebanhos.

O alelo mais freqüente na população total foi o BoLA-DRB3*20. Resultado semelhante foi encontrado por Mota et al. (2004), também na raça Gir, ao investigarem as freqüências alélicas do loco BoLA-DRB3, por meio da técnica de seqüenciamento direto de produtos de PCR, em amostras de sangue obtidas de 28 vacas de outra população. Esses autores verificaram que o alelo mais freqüente foi o BoLA-DRB3*3601, cujo padrão correspondente obtido por PCR-RFLP é o BoLA-DRB3*20.

Mota et al. (2002) observaram alta freqüência do alelo BoLA-DRB3*2101, o qual corresponde ao alelo BoLA-DRB3*35, também muito encontrado em ambos os rebanhos analisados.

Em raças européias especializadas para produção de leite, Sharif et al. (1998b), na raça Holandesa, e Gilliespie et al. (1999), na raça Jersey, observaram maiores freqüências dos alelos *8 e 
$* 10$, respectivamente, enquanto Takeshima et al. (2001), em animais frísios, observaram que o alelo $* 22$ foi o de maior freqüência.

De maneira geral, pode-se verificar que, em bovinos, as interpretações dos resultados obtidos por meio das técnicas de PCR-RFLP e de seqüenciamento indicam que há diferenças significativas nas freqüências alélicas do loco BoLA-DRB3.2 nas raças Jersey (Gilliespie et al., 1999), Holandesa (Dietz et al., 1997), Criola Argentina (Giovambattista et al., 2001), Japanese Black e Japanese Shorthorn (Takeshima et al., 2003) e Gir, como as encontradas por Mota et al. (2002) e neste estudo, o que permite diferenciar e determinar as distâncias genéticas entre as diferentes populações, provendo base molecular para determinação de sua origem comum.

Os efeitos dos alelos DRB3.2 sobre a produção de leite em até 305 dias encontram-se na Tab. 2. Deve-se considerar que a seleção para produção de leite feita dentro de cada rebanho e, conseqüentemente, o descarte de vacas podem ter viesado as estimativas, pois foram considerados, nas análises, os registros do primeiro, segundo e terceiro partos. Ressalte-se que a comparação dos resultados obtidos em diferentes populações deve ser feita com reservas, pois o desequilíbrio de ligação existente dentro de cada uma delas pode ser diferente.

Tabela 2. Efeito de substituição dos alelos BoLA $^{1}$ para a produção de leite em até 305 dias, por rebanho, na raça Gir

\begin{tabular}{ccc}
\hline \multirow{2}{*}{ Alelo BoLA ${ }^{1}$} & \multicolumn{2}{c}{$\hat{\beta} \pm$ EP } \\
\cline { 2 - 3 } 3 & Rebanho A & Rebanho B \\
\hline 5 & & $283,89 \pm 227,77$ \\
6 & & $-38,04 \pm 202,28$ \\
7 & $196,36 \pm 196,82$ & $-74,44 \pm 199,93$ \\
8 & & $434,48 \pm 275,48$ \\
11 & & $230,60 \pm 219,89$ \\
15 & & $197,53 \pm 217,55$ \\
16 & $-155,40 \pm 210,44$ & $382,50 \pm 194,87 *$ \\
18 & & $-215,39 \pm 267,85$ \\
20 & & $132,28 \pm 175,10$ \\
27 & $-13,93 \pm 193,84$ & $-58,33 \pm 185,35$ \\
29 & $-130,43 \pm 177,96$ & $659,76 \pm 335,81 *$ \\
31 & & $163,19 \pm 195,82$ \\
35 & $62,97 \pm 207,73$ & $163,37 \pm 204,83$ \\
42 & $-129,26 \pm 200,12$ & $109,28 \pm 314,28$ \\
51 & & $368,41 \pm 365,00$ \\
54 & & $-187,60 \pm 216,84$ \\
\hline${ }^{1}$ Os alelos com freqüência inferior a $1 \%$ foram eliminados da \\
análise de associação.
\end{tabular}

No rebanho $B$, cuja média \pm erro-padrão da produção de leite em até 305 dias foi igual a $3.024 \pm 73 \mathrm{~kg}$, encontrou-se associação significativa $(\mathrm{P}<0,05)$ entre alelos $* 16$ e $* 29$ e produção de leite. No rebanho $\mathrm{A}$, no qual a média \pm erro-padrão da produção de leite foi igual a $4.698 \pm 94 \mathrm{~kg}$, não foram encontradas associações significativas entre essa característica e os alelos BoLA-DRB3.2, provavelmente devido ao tamanho da amostra.

De acordo com Starkenburg et al. (1997) e Sharif et al. (1998a), o alelo *16, na raça Holandesa, está relacionado a menores escores de células somáticas durante as lactações, refletindo em úberes mais saudáveis e, conseqüentemente, maiores produções. Ainda, esse mesmo alelo pode estar associado a menor incidência de cistos ovarianos e de retenções de placenta (Sharif et al., 1998a), segundo Xu et al. (1993), ele estaria associado ao aumento da persistência linfocitária, o que poderia explicar sua alta freqüência em ambos rebanhos, pois animais mais susceptíveis à mastite e com problemas reprodutivos seriam descartados com o passar dos anos. Tal suposição é reforçada pela baixa freqüência do alelo *23 (Tab. 1), que pode estar associado ao aumento de incidência de mastite clínica (Sharif et al., 1998b).

O padrão para o alelo DRB3. $2 * 29$, obtido por PCR-RFLP, que corresponde ao alelo DRB3.2*4101, foi identificado anteriormente por van Eijk et al. (1992), nas raças South Devon, Angus e Gelbivieh, e por Mota et al. (2002), na raça Gir, mas não foi encontrada na literatura nenhuma referência relacionando esse alelo a alguma característica produtiva. Neste estudo, o alelo *29 estava associado ao aumento significativo na produção de leite em até 305 dias no rebanho $\mathrm{B}$, todavia, em razão de sua baixa freqüência, o resultado pode ter sido ocasional, como reflexo da amostragem.

Os resultados deste estudo mostraram a inexistência de associação entre os demais alelos BoLA e a produção de leite em até 305 dias na raça Gir. As prováveis causas podem ser o tamanho da população analisada, portanto, o reduzido poder estatístico, ou a real ausência de tais associações na população. Também, a inconsistência pode ter sido causada por diferenças no desequilíbrio de ligação ou por associações ocasionais. 
Starkenburg et al. (1997) mostraram efeitos significativos dos alelos $* 3$ e *7, respectivamente, na redução do escore de células somáticas e no aumento da produção de leite e de proteína nas duas primeiras lactações, na raça Holandesa, enquanto o alelo $* 8$ estava associado a reduções nas produções de leite e de proteína. Sharif et al. (1998a) relataram associação significativa do alelo $* 3$ e menores riscos de retenção de placenta.

Sharif et al. (1998b) mostraram que o alelo *11 não estava associado a alterações nas produções de leite, de gordura e de proteína, enquanto Dietz et al. (1997) descreveram associação genética entre alelos BoLA, dentre eles o alelo *27, e vários indicadores de imunidade inata $\mathrm{e}$ adaptativa em vacas holandesas.

Para os demais alelos (BoLA-DRB3.2*5, *6, $* 15, * 18, * 20, * 31, * 35, * 42, * 51$ e *54) não foram encontradas na literatura quaisquer referências em estudos de associação com características de produção, de reprodução ou de resistência a doenças.

Procurou-se, também, verificar a existência de possíveis interações entre os alelos, por meio da análise conjunta dos genótipos dos animais, mas não foram encontrados resultados significativos.

Mota et al. (2002) argumentaram que uma fonte de incerteza relacionada ao loco BoLA-DRB3, é a falta de estudos do gado Zebu nas regiões tropicais. Apesar dos resultados pouco consistentes sobre a associação entre alelos BoLA e a produção de leite em até 305 dias devido ao limitado número de animais, este trabalho certamente contribuiu para maior conhecimento desse loco dentro da raça Gir, uma vez que foram identificados 13 alelos não encontrados por Mota et al. (2002), e sete novos alelos que não haviam sido relatados em raças zebuínas. Deve-se ressaltar que praticamente todos os estudos, que procuraram identificar possíveis associações entre alelos BoLADRB3.2, analisaram menor número de informações que este estudo. Como exemplo, podem ser citados os trabalhos de Lunden et al. (1993), Dietz et al. (1997), Kelm et al. (1997) e Gilliespie et al. (1999), os quais analisaram, respectivamente, 196, 127, 137 e 172 registros de produção e genótipos.
A potencial utilização dos alelos BoLA como marcadores de características de produção pode ser de menor importância, desde que a seleção tradicional seja bastante efetiva (Weigel et al., 1990). Além disso, se a seleção é praticada por muitas gerações, seria improvável que um gene de efeito maior benéfico não estivesse fixado na população, a menos que ele tivesse algum efeito deletério.

A seleção direta para resistência a doenças é pouco efetiva, tanto pela baixa herdabilidade dessas características quanto pela dificuldade e/ou complexidade de sua mensuração e avaliação. Deste modo, a aplicação da seleção assistida por marcadores e de técnicas de manipulação usando genes do complexo BoLA pode auxiliar na seleção para maior resistência a doenças, tendo como conseqüência indireta o aumento da produção de leite em razão das melhores condições gerais de saúde dos animais.

\section{CONCLUSÕES}

Há grande polimorfismo no loco BoLA-DRB3.2 na raça Gir, com identificação de sete alelos ainda não citados em raças zebuínas. Foram encontradas associações significativas dos alelos *16 e *29 com maiores produções de leite.

\section{REFERÊNCIAS BIBLIOGRÁFICAS}

ALIZADEH, Z.; KARROW, N.; MALLARD, B.A. Biological effect of varying peptide binding affinity to the BoLA-DRB3*2103 allele. Genet. Sel. Evol., v.35, Suppl. 1, p.S51-S65, 2003.

ARRIENS, M.A.; HOFER, A.; OBEXER-RUFF, G. et al. Associations of serologically defined BoLA class I alleles with milk-production traits in 3 Swiss cattle breeds. Livest. Prod. Sci., v.45, p.163-169, 1996.

BATRA, T.R.; LEE, A.J.; GAVORA, J.S. et al. Class I alleles of the bovine major histocompatibility system and their associations with economic traits. J. Dairy Sci., v.72, p.21152124, 1989.

BATRA, T.R.; STEAR, M.J.; MACDONALD, P.A. Association of class I bovine lymphocyte antigens with profitability and lifetime yields in the Holstein breed. J. Anim. Sci., v.76, p.145$148,1996$. 
DEITILLEUX, J.C. Genetic study of immunological parameters in periparturient Holstein cows. 1993. 74f. Dissertation (Ph D) Iowa State University, Ames, Iowa.

DIETZ, A.B.; DETILLEUX, J.C.; FREEMAN, A.E. et al. Genetic association of bovine lymphocyte antigen DRB3 alleles with immunological traits of Holstein cattle. J. Dairy Sci., v.80, p.400-405, 1997.

FRIES, R.; BECKMANN, J.S.; GEORGES, M. et al. The bovine gene map. Anim. Genet., v.20, p.3-29, 1988.

GILLIESPIE, B.E.; JAYARAO, B.M.; DOWLEN, H.H. et al. Analysis and frequency of bovine lymphocyte antigen DRB3.2 alleles in Jersey cows. J. Dairy Sci., v.82, p.2049-2053, 1999.

GIOVAMBATTISTA, G.; RIPOLI, M.V.; PERAL-GARCIA, $P$. et al. Indigenous domestic breeds as reservoirs of genetic diversity: the Argentinean Creole cattle. Anim. Genet., v.32, p.240-247, 2001.

HINES, H.C.; ALLAIRE, F.R.; MICHALAK, M.M. Association of bovine lymphocyte antigens with milk fat percentage differences. $J$. Dairy Sci., v.69, p.3148-3150, 1986.

INTERNATIONAL BOVINE LYMPHOCYTE ANTIGEN (BoLA), 5., 1992, Interlaken, Switzerland. [s.1.]; [s.n.], 1992. Disponível em: $<$ http://www.projects.roslin.ac.uk/bola/wk92b.ht ml>. Acesso em: 10 dez. 2003.

ISRAEL, C.; WELLER, J.I. Estimation of candidate genes effects in dairy cattle populations. J. Dairy Sci., v.81, p.1653-1662, 1998.

KELM, S.C.; DEITILLEUX, J.C.; FREEMAN, A.E. et al. Genetic association between parameters of innate immunity and measures of mastitis in periparturient Holstein cattle. J. Dairy Sci., v.80, p.1767-1775, 1997.

LEWIN, H.A.; WU, M.C.; STEWART, J.A. et al. Association between BoLA and subclinical bovine leukosis virus infection in a herd of Holstein-Friesian cows. Immunogenetics, v.27, p.338, 1988.

LUNDEN, A.; ANDERSSON-EKLUND, L; ANDERSSON, L. Lack of association between bovine major histocompatibility complex class II polymorphism and production traits. J. Dairy
Sci., v.76, p.843-852, 1993.

MAILLARD, J.C.; BERTHIER, D.; CHANTAL, I. et al. Selection assisted by a BoLA-DR/DQ haplotype against susceptibility to bovine dermatophilosis. Genet. Sel. Evol., v.35, Suppl. 1, p. S193-S200, 2003.

MAILLARD, J.C.; RENARD, C.; CHARDON, P. et al. Characterization of 18 new BoLA-DRB3 alleles. Anim. Genet., v.30, p.200-203, 1999.

MEJDELL, C.M.; LIE, O.; SOLBU, H. et al. Association of major histocompatibility complex antigens (BoLA-A) with AI bull progeny test results for mastitis, ketosis and fertility in Norwegian cattle. Anim. Genet., v.19, p.11-16, 1994.

MOTA, A.F.; GABRIEL, J.E.; MARTINEZ, M.L. et al. Distribution of bovine lymphocyte antigen (BoLA-DRB3) alleles in Brazilian dairy Gir cattle (Bos indicus). Europ. J. Immunogen., v.29, p.223-227, 2002.

MOTA, A.F.; MARTINEZ, M.L.; COUTINHO, L.L. Genotyping BoLA-DRB3 alleles in Brazilian Dairy Gir cattle (Bos indicus) by temperature-gradient gel electrophoresis (TGGE) and direct sequencing. Europ. J. Immunogen., v.31, p.31-35, 2004.

ROTHSCHILD, M.F.; SOLLER, M. Candidate analysis to detect genes controlling traits of economic importance in domestic livestock. Probe, v.8, p.13-19, 1997.

SENA, L.; SCHNEIDER, M.P.; BRENIG, B. et al. Polymorphisms in MHC-DRA and -DRB alleles of water buffalo (Bubalus bubalis) reveal different features from cattle DR alleles. Anim. Genet., v.34, p.1-10, 2003.

SHARIF, S.; MALLARD, B.A.; WILKIE, B.N. Characterization of naturally processed and presented peptides associated with bovine major histocompatibility complex (BoLA) class II DR molecules. Anim. Gen., v.34, p.116-123, 2003.

SHARIF, S.; MALLARD, B.A.; WILKIE, B.N. et al. Associations of the bovine major histocompatibility complex DRB3 (BoLADRB3) occurrence of disease and milk somatic cell score in Canadian dairy cattle. Anim. Genet., v.29, p.185-193, 1998a.

SHARIF, S.; MALLARD, B.A.; WILKIE, B.N. et al. Associations of the bovine major histocompatibility complex DRB3 (BoLA) with 
production traits in Canadian dairy cattle. Anim. Genet., v.30, p.157-160, 1998b.

STARKENBURG, R.J.; HANSEN, L.B.; KEHRLI, M.E. et al. Frequencies and effects of alternative DRB3.2 alleles of bovine lymphocyte antigen for Holsteins in milk selection and control lines. J. Dairy Sci., v.80, p.3411-3419, 1997.

TAKESHIMA, S.; IKEGAMI, M.; MORITA, M. et al. Identification of new cattle BoLA-DRB3 alleles by sequence-based typing. Immunogenetics, v.53, p.74-81, 2001.

TAKESHIMA, S.; SAITOU, N.; MORITA, M. et al. The diversity of bovine MHC class II DRB3 genes in Japanese Black, Japanese Shorthorn, Jersey and Holstein cattle in Japan. Gene, v.316, p.111-118, 2003.
USER'S guide: basic and statistics. Cary, NC: SAS Institute, 2000.

van EIJK, M.J.T.; STEWART-HAYNES, J.A.; LEWIN, H.A. Extensive polymorphism of the BoLA-DRB3 gene distinguished by PCR-RFLP. Anim. Gen., v.23, p.483-496, 1992.

WEIGEL, K.A.; FREEMAN, A.E.; KEHRLI Jr., M.E. et al. Association of class I bovine lymphocyte antigen complex alleles with health and production traits in dairy cattle. J. Dairy Sci., v.73, p.2538-2546, 1990.

XU, A.; van EIJK, M.J.T.; PARK, C. et al. Polymorphism in BoLA-DRB3 exon 2 correlates with resistance to persistent lymphocytosis caused by bovine leukaemia virus. J. Immunol., v.151, p.6977-6985, 1993. 